
\title{
3 Research Soure \\ The efficacy of deep learning models in the diagnosis of endometrial cancer using MRI: A comparison with radiologists
}

\section{Aiko Urushibara}

University of Tsukuba

\section{Tsukasa Saida}

University of Tsukuba

Kensaku Mori

University of Tsukuba

Toshitaka Ishiguro

University of Tsukuba

Kei Inoue

University of Tsukuba

Toyomi Satoh

University of Tsukuba

\section{Tomohiko Masumoto}

Toranomon Hospital

Takahito Nakajima ( $\square$ nakajima@md.tsukuba.ac.jp )

University of Tsukuba

\section{Research Article}

Keywords: endometrial carcinoma, artificial intelligence, convolutional neural network, CNN, magnetic resonance imaging

Posted Date: January 27th, 2022

DOI: https://doi.org/10.21203/rs.3.rs-1224867/v1

License: (c) (1) This work is licensed under a Creative Commons Attribution 4.0 International License. Read Full License 


\section{Abstract}

Purpose: To compare the diagnostic performance of deep learning models using convolutional neural networks (CNN) with that of radiologists in diagnosing endometrial cancer and to verify suitable imaging conditions. Methods: This retrospective study included patients with endometrial cancer or noncancerous lesions who underwent MRI between 2015 and 2020. In Experiment 1, single and combined image sets of several sequences from 204 patients with cancer and 184 patients with non-cancerous lesions were used to train CNNs. Subsequently, testing was performed using 97 images from 51 patients with cancer and 46 patients with non-cancerous lesions. The test image sets were independently interpreted by three blinded radiologists. Experiment 2 investigated whether the addition of different types of images for training using single image sets improved the diagnostic performance of CNNs. Results: The AUC of the CNNs pertaining to single and combined image sets were $0.88-0.95$ and $0.87-0.93$, respectively, indicating better or equivalent diagnostic performance than the radiologists. The AUC of the CNNs trained with the addition of other types of images was $0.88-0.95$. Conclusion: CNNs demonstrated high diagnostic performance for the diagnosis of endometrial cancer using MRI. Although there were no significant differences, adding other types of images improved the diagnostic performance for some image sets.

\section{Background}

Endometrial cancer is the sixth most common malignant disorder in women worldwide (1). About 417,000 new cases of endometrial cancer were diagnosed worldwide in 2020, and about 97,000 people died from this disease (1). The incidence of endometrial cancer is on the rise (2). Surgery and biopsy are the standards for staging endometrial cancer, and MRI can assist in preoperative evaluation and surgical planning by accurately predicting the depth of invasion into the myometrium, invasion of the cervical stroma and surrounding organs, and the presence of lymph node metastases $(3,4)$. Recently, multiparametric MRI has been introduced to improved diagnosis (5). In case, the biopsy is not possible due to closure of the internal uterine ostium or no experience of sexual intercourse, MRI is also used to diagnose the presence of endometrial cancer (3). Although MRI has not been formally incorporated into the FIGO staging system, it is already widely accepted as the most reliable imaging technique for diagnosing, staging, treatment planning, and follow-up of endometrial cancer. Moreover, MRI is said to minimize costs by eliminating the need for expensive diagnostic and surgical procedures (3).

In recent years, deep learning methods based on convolutional neural networks (CNN) have achieved remarkable performance in image pattern recognition $(6,7)$. Moreover, a wide variety of computer vision tasks have been reported in the literature including deep learning-based segmentation (8-10), lesion detection $(11,12)$, and classification $(13,14)$. The diagnostic modalities that were investigated include ultrasound, radiograph, CT, and MRI. The application of CNN to tumor images has the potential to be applied not only to image interpretation assist, but also to screening, prognosis estimation, and selection of optimal treatment methods, and we believe that tumor detection is the first step. However, to the best of our knowledge, no previous study has developed a CNN for diagnosing the presence of endometrial 
cancer. In addition, few studies have investigated the optimal image conditions for MR image classification using deep learning with several sequences and cross-sections.

The present study constructed CNNs for diagnosing endometrial cancer using several MR images and its combination to validate for optimal CNN imaging conditions, and compared their diagnostic performance with that of experienced radiologists. Furthermore, we verified whether the diagnostic performance could be improved by the addition of sequences and cross sections, other than the same type as the test image set, to the training data.

\section{Materials And Methods}

\subsection{Study design}

The current, retrospective study was approved by the Institutional Review Board of our institution and the requirement for written informed consent was waived (approval number: R02-054). The inclusion criteria are stated as follows: (A) woman above 20 years of age, (B) pelvic MRI scan obtained as per the protocol followed at our hospital during the time period from January 2015 to May 2020, (C) hysterectomized and pathologically confirmed as endometrial cancer (cancer group), and (D) pathologically or clinically definitely benign lesions (non-cancer group). The exclusion criteria are stated as follows: (A) history of treatment for uterine diseases and (B) macroscopically non-mass-forming cancers according to pathological reports. A flowchart for the patient selection process is presented in Figure 1.

Figure 2 shows a flow diagram of the study design. As shown in Figure 2a, Experiment 1 constructed CNNs for diagnosing the presence of endometrial cancer. Single and combined image sets of T2weighted image (T2WI), apparent diffusion coefficient of water (ADC) map, and contrast-enhanced T1weighted image (CE-T1WI) were used to validate optimal imaging conditions for $\mathrm{CNN}$, and we compared their diagnostic performance with those of experienced radiologists. As shown in Figure 2b, Experiment 2 verified whether the diagnostic performance could be improved by the addition of sequences and cross sections, other than the same type as the test image set, to the training data.

\subsection{MRI acquisition}

The MRI scan was performed using 3T or 1.5T equipment (Ingenia ${ }^{\circledR}$, Achieva ${ }^{\circledR}$; Philips Medical Systems, Netherlands) with a 32-channel phased-array body coil. The protocol employed to obtain the image of the entire uterus along the uterine axis included T2Wls, Diffusion weighted images (DWls) (b-value: 0,1000$)$, and CE-T1Wls of the equilibrium phase (Table 1). Gadopentetate dimeglumine $5 \mathrm{mmol}$ (Magnevist ${ }^{\circledR} 0.5$ $\mathrm{mol} / \mathrm{L}$ or Gadovist ${ }^{\circledR} 1.0 \mathrm{~mol} / \mathrm{L}$; Bayer, Germany) was used for CE-T1Wls. The gadolinium dose varied according to the patient's weight, as recommended $(0.2 \mathrm{ml} / \mathrm{kg})$. Bolus intravenous contrast injection rate was $4 \mathrm{~mL}(2 \mathrm{mmol}) / \mathrm{sec}$ (in case of Gadovist, dilute with saline solution and inject at $4 \mathrm{ml} / \mathrm{sec}$ ). 
Table 1

MRI acquisition parameters

\begin{tabular}{|c|c|c|c|c|c|c|c|c|}
\hline Scanner & Sequence & $\begin{array}{l}\text { Cross- } \\
\text { section }\end{array}$ & Type & $\begin{array}{l}\text { TR/TE } \\
\text { (ms) }\end{array}$ & $\begin{array}{l}\text { FA } \\
\text { (degree) }\end{array}$ & $\begin{array}{l}\text { Slice/Gap } \\
(\mathrm{mm})\end{array}$ & $\begin{array}{l}\text { FOV } \\
(\mathrm{mm})\end{array}$ & Matrix \\
\hline \multirow[t]{5}{*}{$\begin{array}{l}\text { Ingenia }{ }^{\circledR} \\
\text { 3.0T }\end{array}$} & $\mathrm{T} 2 \mathrm{WI}$ & $\mathrm{Sg}$ & $\begin{array}{l}\text { 2D- } \\
\text { TSE }\end{array}$ & $1400 / 110$ & 90 & $\begin{array}{l}3-5 / 0.3- \\
0.5\end{array}$ & 280 & $\begin{array}{l}640 \times \\
640\end{array}$ \\
\hline & $\mathrm{T} 2 \mathrm{Wl}$ & $A x$ & $\begin{array}{l}\text { 2D- } \\
\text { TSE }\end{array}$ & $\begin{array}{l}4955- \\
5789 / 100- \\
110\end{array}$ & 90 & $\begin{array}{l}3-5 / 0.3- \\
0.5\end{array}$ & 280 & $\begin{array}{l}704 \times \\
704\end{array}$ \\
\hline & DWI & $A x$ & EPI & $\begin{array}{l}6500- \\
7500 / 77- \\
79\end{array}$ & 90 & $\begin{array}{l}3-5 / 0.3- \\
0.5\end{array}$ & 280 & $\begin{array}{l}224 \times \\
224\end{array}$ \\
\hline & CE-T1WI & $\mathrm{Sg}$ & $\begin{array}{l}\text { 3D- } \\
\text { GRE } \\
\text { SPIR }\end{array}$ & $4 / 2$ & 10 & $3.3 / 1.6$ & 280 & $\begin{array}{l}576 \times \\
576\end{array}$ \\
\hline & CE-T1WI & $A x$ & $\begin{array}{l}\text { 3D- } \\
\text { GRE } \\
\text { SPIR }\end{array}$ & $4 / 2$ & 10 & $3.3 / 1.6$ & 280 & $\begin{array}{l}576 \times \\
576\end{array}$ \\
\hline \multirow[t]{5}{*}{$\begin{array}{l}\text { Achiva }{ }^{\circledR} \\
1.5 \mathrm{~T}\end{array}$} & $\mathrm{~T} 2 \mathrm{Wl}$ & $\mathrm{Sg}$ & $\begin{array}{l}\text { 2D- } \\
\text { TSE }\end{array}$ & $\begin{array}{l}1400 / 100- \\
110\end{array}$ & 90 & $\begin{array}{l}3-5 / 0.3- \\
0.5\end{array}$ & 280 & $\begin{array}{l}512 \times \\
512- \\
640 \times \\
640\end{array}$ \\
\hline & $\mathrm{T} 2 \mathrm{WI}$ & $A x$ & $\begin{array}{l}\text { 2D- } \\
\text { TSE }\end{array}$ & $\begin{array}{l}1400- \\
6013 / 100- \\
110\end{array}$ & 90 & $\begin{array}{l}3-5 / 0.3- \\
0.5\end{array}$ & 280 & $\begin{array}{l}512 \times \\
512- \\
704 \times \\
704\end{array}$ \\
\hline & DWI & $A x$ & EPI & $\begin{array}{l}3963- \\
7500 / 70- \\
77\end{array}$ & 90 & $\begin{array}{l}3-5 / 0.3- \\
0.5\end{array}$ & 280 & $\begin{array}{l}224 \times \\
224- \\
256 \times \\
256\end{array}$ \\
\hline & CE-T1WI & $\mathrm{Sg}$ & $\begin{array}{l}\text { 3D- } \\
\text { GRE } \\
\text { SPIR }\end{array}$ & $4-5 / 2$ & 15 & $4.4 / 2.2$ & 280 & $\begin{array}{l}336 \times \\
336- \\
576 \times \\
576\end{array}$ \\
\hline & CE-T1WI & $A x$ & $\begin{array}{l}\text { 3D- } \\
\text { GRE } \\
\text { SPIR }\end{array}$ & $5 / 2$ & 15 & $2 / 1$ & $\begin{array}{l}250- \\
280\end{array}$ & $\begin{array}{l}320 \times \\
320- \\
576 \times \\
576\end{array}$ \\
\hline $\begin{array}{l}\text { TR, repetit } \\
\text { spin echo } \\
\text { recovery. }\end{array}$ & $\begin{array}{l}\text { time; TE, e } \\
\text { PI, echo plar }\end{array}$ & $\begin{array}{l}\text { ho time; } \\
\text { ar imaqin }\end{array}$ & , flip a & $\begin{array}{l}\text {; FOV, field } \\
\text { gradient e }\end{array}$ & $\begin{array}{l}\text { iew; Sg, } \\
\text { spectral }\end{array}$ & $\begin{array}{l}\text { gittal; } A x, \text { ax } \\
\text { e-saturation }\end{array}$ & $\begin{array}{l}\text { l; TSE, } \\
\text { with inv }\end{array}$ & $\begin{array}{l}\text { rbo- } \\
\text { sion }\end{array}$ \\
\hline
\end{tabular}

2.3. Data set 
The image slices comprising the endometrium were extracted to create a dataset. In the cancer group, the sequences and pathological findings were considered and only the image slices depicting the tumor were visualized and extracted, as per the consensus of two radiologists (A.U., T.S.). The same cross-sectional images were extracted for all the sequences.

A total of 485 patients were randomly assigned to the training and testing groups. In the training phase, images obtained from 388 patients (204 and 184 patients in the cancer and non-cancer groups, respectively) were used; 2,905 axial images (1,471 and 1,434 images in the cancer and non-cancer groups, respectively) were used in each T2WI, ADC map, and CE-T1Wl; 1,105 sagittal images (624 and 481 images in the cancer and non-cancer groups, respectively) were used in both T2WI and CE-T1WI. In the testing phase, only one central image of the stack was extracted, and 97 images (51 and 46 images from the cancer and non-cancer groups, respectively) were used in each sequence and cross-section.

The digital imaging and communications in medicine (DICOM) images were converted to joint photographic experts group (JPEG) images using the viewing software Centricity Universal Viewer (GE Healthcare, Chicago, Illinois, United States) because the graphical deep learning software we used could not handle the DICOM data itself. Subsequently, the JPEG images were resized to $240 \times 240$ pixels by trimming the margins using the XnConvert (Gougelet Pierre-Emmanuel in Reims, France), in order to perform the analysis. Along with the five single image sets, four combined image sets, including axial T2WI + ADC map, axial T2WI + CE-T1WI, sagittal T2WI + CE-T1WI, and axial T2WI + ADC map + CE-T1WI, were created for training and testing. The axial images were vertically combined ( $240 \times 480$ or $240 \times 720$ pixels) and the sagittal images were horizontally combined (480 x 240 pixels) using ImageMagick (15).

\subsection{Experiment 1: Diagnostic performance for single and combined image sets: CNN vs. radiologists}

The current study compared the diagnostic performance of the CNNs and three board certificated radiologists with 27, 26, and 9 years of experience in pelvic MRI interpretation (T.M., K.M., and T.I.) using five single image sets and four combined image sets. The same types of single or combined image sets were used for training and testing. The radiologists were blinded to the clinical and pathological findings and independently reviewed the 97 randomly ordered test images in each image set and reported the presence or absence of cancer. The interpretation commenced with single image sets (ADC map first), followed by combined image sets. A time interval of one week was maintained between the sessions of interpretation.

\subsection{Experiment 2: CNN in testing single image sets using different image sets for training}

Experiment 2 investigated whether the addition of different types of image sets for training improved the diagnostic performance of CNNs. The CNN was trained using images of the same sequence regardless of the cross-sections, same cross-sectional images regardless of the sequences, and all images regardless 
of the sequences and cross-sections, in order to test five single image sets; only single image sets were used for training and testing.

\subsection{Deep learning with convolutional neural networks}

Deep learning was conducted on Deep Station Entry (UEl, Tokyo, Japan) with a GeForce RTX 2080Ti graphics processing unit (NVIDIA, Calif, USA), a Core i7-8700 central processing unit (Intel, Calif, USA), and the graphical deep learning software Deep Analyzer (GHELIA, Tokyo, Japan). The conditions optimized based on the ablation and comparative studies of the previous research were as follows: CNN with Xception architecture (16) was used for deep learning and ImageNet (17) which consists of natural images was used as pre-training. The parameters of optimization are stated as follows: optimizer algorithm = Adam (learning rate $=0.0001, \beta 1=0.9, \beta 2=0.999$, eps $=$ le-7, decay $=0$, AMSGrad $=$ false) . The batch size was automatically selected. Horizontal flip, rotation $\left( \pm 4.5^{\circ}\right)$, shearing $(0.05)$, and zooming (0.05) were automatically used as the data augmentation techniques. The CNNs were generated by setting the training/validation split ratio to $9: 1,8: 2$, or 7:3, and the epochs to $50,100,200,500$ or 1000 and the diagnostic results of each were validated. The training/validation split ratio and epochs were selected for each image set on the basis of the best performance among the CNNs with sensitivity and specificity above 0.75 (Table 2 ). 
Table 2

The best settings for training/validation split ratio and epoch in Experiment 1 and 2

Test image set

Training image set
Training/validation split ratio

\section{Experiment 1}

Axial ADC map

Axial T2WI

Sagittal T2WI

Axial CE-T1WI

Sagittal CE-T1WI

Combined axial T2WI + ADC

map

Combined axial T2WI + CE-

T1WI

Combined sagittal T2WI + CE-

T1WI

Combined axial T2WI + ADC

map + CE-T1WI
Axial ADC map

Axial T2WI

Sagittal T2WI

Axial CE-T1WI

Sagittal CE-T1WI

Combined axial T2WI + ADC

map

Combined axial T2WI + CE-

T1WI

Combined sagittal T2WI + CE-

T1WI

Combined axial T2WI + ADC map+ CE-T1WI
$9: 1$

9:1

8:2

8:2

$8: 2$

9:1

$9: 1$

9:1

50

9:1 200

\section{Experiment 2}

\begin{tabular}{llll} 
Axial ADC map & All axial & $8: 2$ & 50 \\
Axial ADC map & All & $9: 1$ & 50 \\
Axial T2WI & All T2WI & $8: 2$ & 100 \\
Axial T2WI & All axial & $9: 1$ & 50 \\
\hline Axial T2WI & All & $9: 1$ & 50 \\
\hline Sagittal T2WI & All T2WI & $8: 2$ & 200 \\
\hline Sagittal T2WI & All sagittal & $8: 2$ & 200 \\
\hline Sagittal T2WI & All & $8: 2$ & 100 \\
\hline Axial CE-T1WI & All CE-T1WI & $8: 2$ & 50 \\
\hline Axial CE-T1WI & All axial & $8: 2$ & 100 \\
\hline Axial CE-T1WI & All & $8: 2$ & 100 \\
Sagittal CE-T1WI & All CE-T1WI & $9: 1$ & 100
\end{tabular}

T2WI, T2 weighted image; ADC, Apparent Diffusion Coefficient; CE, contrast enhanced. 


\begin{tabular}{|llll|}
\hline Test image set & Training image set & $\begin{array}{l}\text { Training/validation } \\
\text { split ratio }\end{array}$ & Epoch \\
\hline Sagittal CE-T1WI & All sagittal & $9: 1$ & 50 \\
\hline Sagittal CE-T1WI & All & $9: 1$ & 100 \\
\hline T2WI, T2 weighted image; ADC, Apparent Diffusion Coefficient; CE, contrast enhanced. & \\
\hline 2.7. Statistical analysis & &
\end{tabular}

Statistical analyses were conducted using EZR (Saitama Medical Center, Jichi Medical University, Saitama, Japan), a graphical user interface for R (The R Foundation for Statistical Computing, Vienna, Austria), and SPSS software (SPSS Statistics 27.0; IBM, New York, NY, USA). The clinical values for each group were compared using the Mann-Whitney $U$ test and the chi-square test. The test data set was used to evaluate the sensitivity, specificity, and accuracy in cancer diagnosis. The receiver operating characteristic (ROC) analysis was performed to evaluate the diagnostic performance (18). For statistics, 95\% confidence intervals (Cls) and significant differences were estimated. $P<0.05$ was considered to be significant.

\section{Results}

\subsection{Patients and tumor characteristics from the training and test cohort}

A total of 485 women (mean age, 52 years; age range, 21-91 years) were evaluated across the datasets. Table 3 shows the characteristics pertaining to the patients, the pathological types, and the number of each image. Although the patients in the cancer group were substantially older, compared to the noncancer group $(P<0.001)$, the present study did not observe any significant difference between the training and test data with respect to the age of the patients $(P=0.817)$. In the cancer group, 194 patients (train; 153, test; 41) were scanned with 3T equipment, and 61 patients (train; 51, test; 10) were scanned with 1.5T equipment. Also, in the non-cancer group, 166 patients (train; 131, test; 35) were scanned with $3 T$ equipment and 64 patients (train; 53 , test; 11 ) were scanned with $1.5 \mathrm{~T}$ equipment. There was no significant difference in imaging equipment between the cancer group and the non-cancer group (train; $P=0.465$ test; $P=0.789$ ), and there was no significant difference in imaging equipment between training andtesting (cancer; $P=0.533$ non-cancer; $P=0.633$ ). Of all, 55 patients in the non-cancer group (train; 47, test; 8) were clinically confirmed including imaging findings rather than pathological, and all others were pathologically confirmed. 
Table 3

Characteristics of the patients and lesions

Training data

Cancer

204

$58 \pm$

11.50

28-83
$46 \pm$

12.00

22-81
Test data

All

cancer

$184 \quad 388$

93

16

71

$52 \pm$

13.00

$60 \pm$

13.74

$44 \pm$

12.53

$53 \pm$

$22-83 \quad 30-91 \quad 21-71 \quad 21-91$

24

\section{Pathological type (n)}

Benign ( $\mathrm{n}$ )

Benign ovarian tumor

Leiomyoma

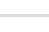

Endometrial hyperplasia

25

Nabothian cyst

17

6

Other

40

\section{3}

7

\section{Malignant ( $\mathrm{n}$ )}

EC grade 1

EC grade 2

EC grade 3

Other ECs

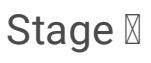

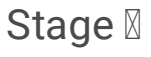

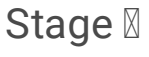

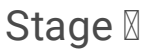

Images ( $\mathrm{n}$ )

Axial (T2WI, ADC map,

1471

1434

2905
30

11

9

1

37

4

5

5

CE-T1WI)

SD, standard deviation; EC, Endometrioid carcinoma; T2WI, T2 weighted image; ADC, Apparent Diffusion Coefficient; CE, contrast enhanced. 


\begin{tabular}{|c|c|c|c|c|c|c|}
\hline \multirow[b]{2}{*}{$\begin{array}{l}\text { Sagittal (T2WI, CE- } \\
\text { T1WI) }\end{array}$} & \multicolumn{3}{|c|}{ Training data } & \multicolumn{3}{|c|}{ Test data } \\
\hline & 619 & 480 & 1099 & 51 & 46 & 97 \\
\hline
\end{tabular}

\subsection{Experiment 1}

The results of Experiment 1 are presented in Table 4 and Figure 3. Table 4 shows the diagnostic performance of the CNNs and radiologists for single and combined image sets and Figure 3 shows the ROC curve comparing the performance of the CNNs for single and combined image sets with the area under the receiver operating characteristic curve (AUC) pertaining to the radiologists. The sensitivity, specificity, accuracy, and AUC of the CNNs using both the single and combined image sets were comparable to those displayed by the three radiologists. The AUC of the CNN was significantly higher for axial ADC map and axial CE-T1WI, compared to the three radiologists, and on axial T2WI, compared to reader 2 , and combined axial T2WI+ ADC map, compared to reader 1 . The present study did not observe any other significant difference between the CNNs and the three radiologists. The CNN showed the highest diagnostic performance with single axial ADC map with an AUC of 0.95 , the graphs of accuracy and loss of training data of single ADC map are shown in Figure 4. The AUC of the CNNs for combined axial T2WI + ADC map + CE-T1WI was 0.87 , which was the lowest among the CNNs' results for all the single and combined image sets. 
Table 4

Experiment 1-Diagnostic performance of the CNNs and radiologists

\begin{tabular}{|c|c|c|c|c|c|c|}
\hline Image set & Interpreter & Sensitivity & Specificity & Accuracy & AUC & $\begin{array}{l}P \text { value } \\
\text { for AUC } \\
\text { (vs. } \\
\text { CNN) }\end{array}$ \\
\hline \multirow[t]{4}{*}{ Axial ADC map } & CNN & $\begin{array}{l}0.94 \\
(0.87- \\
0.98)\end{array}$ & $\begin{array}{l}0.87 \\
(0.79- \\
0.91)\end{array}$ & $\begin{array}{l}0.91 \\
(0.83- \\
0.95)\end{array}$ & $\begin{array}{l}0.95 \\
(0.91- \\
1.00)\end{array}$ & - \\
\hline & Reader1 & $\begin{array}{l}0.71 \\
(0.56- \\
0.83)\end{array}$ & $\begin{array}{l}0.85 \\
(0.71- \\
0.94)\end{array}$ & $\begin{array}{l}0.77 \\
(0.68- \\
0.85)\end{array}$ & $\begin{array}{l}0.78 \\
(0.70- \\
0.86)\end{array}$ & $<0.001^{*}$ \\
\hline & Reader2 & $\begin{array}{l}0.67 \\
(0.52- \\
0.79)\end{array}$ & $\begin{array}{l}0.87 \\
(0.74- \\
0.95)\end{array}$ & $\begin{array}{l}0.76 \\
(0.67- \\
0.84)\end{array}$ & $\begin{array}{l}0.77 \\
(0.69- \\
0.85)\end{array}$ & $<0.001^{\star}$ \\
\hline & Reader3 & $\begin{array}{l}0.77 \\
(0.63- \\
0.87)\end{array}$ & $\begin{array}{l}0.78 \\
(0.63- \\
0.87)\end{array}$ & $\begin{array}{l}0.77 \\
(0.68- \\
0.85)\end{array}$ & $\begin{array}{l}0.77 \\
(0.69- \\
0.86)\end{array}$ & $<0.001^{\star}$ \\
\hline \multirow[t]{4}{*}{ Axial T2WI } & CNN & $\begin{array}{l}0.90 \\
(0.83- \\
0.95)\end{array}$ & $\begin{array}{l}0.83 \\
(0.74- \\
0.88)\end{array}$ & $\begin{array}{l}0.87 \\
(0.79- \\
0.92)\end{array}$ & $\begin{array}{l}0.90 \\
(0.84- \\
0.96)\end{array}$ & - \\
\hline & Reader1 & $\begin{array}{l}0.73 \\
(0.58- \\
0.84)\end{array}$ & $\begin{array}{l}0.96 \\
(0.85- \\
1.00)\end{array}$ & $\begin{array}{l}0.84 \\
(0.75- \\
0.90)\end{array}$ & $\begin{array}{l}0.84 \\
(0.77- \\
0.91)\end{array}$ & 0.220 \\
\hline & Reader2 & $\begin{array}{l}0.61 \\
(0.46- \\
0.74)\end{array}$ & $\begin{array}{l}0.94 \\
(0.82- \\
0.99)\end{array}$ & $\begin{array}{l}0.76 \\
(0.67- \\
0.84)\end{array}$ & $\begin{array}{l}0.77 \\
(0.70- \\
0.85)\end{array}$ & $0.015^{\star}$ \\
\hline & Reader3 & $\begin{array}{l}0.73 \\
(0.58- \\
0.84)\end{array}$ & $\begin{array}{l}0.91 \\
(0.79- \\
0.98)\end{array}$ & $\begin{array}{l}0.81 \\
(0.72- \\
0.89)\end{array}$ & $\begin{array}{l}0.82 \\
(0.75- \\
0.89)\end{array}$ & 0.100 \\
\hline \multirow[t]{4}{*}{ Sagittal T2WI } & $\mathrm{CNN}$ & $\begin{array}{l}0.90 \\
(0.82- \\
0.95)\end{array}$ & $\begin{array}{l}0.80 \\
(0.72- \\
0.86)\end{array}$ & $\begin{array}{l}0.86 \\
(0.77- \\
0.91)\end{array}$ & $\begin{array}{l}0.88 \\
(0.81- \\
0.95)\end{array}$ & - \\
\hline & Reader1 & $\begin{array}{l}0.69 \\
(0.54- \\
0.81)\end{array}$ & $\begin{array}{l}1.00 \\
(0.89- \\
1.00)\end{array}$ & $\begin{array}{l}0.84 \\
(0.75- \\
0.90)\end{array}$ & $\begin{array}{l}0.84 \\
(0.78- \\
0.91)\end{array}$ & 0.457 \\
\hline & Reader2 & $\begin{array}{l}0.77 \\
(0.63- \\
0.87)\end{array}$ & $\begin{array}{l}0.94 \\
(0.82- \\
0.99)\end{array}$ & $\begin{array}{l}0.85 \\
(0.76- \\
0.91)\end{array}$ & $\begin{array}{l}0.85 \\
(0.78- \\
0.92)\end{array}$ & 0.574 \\
\hline & Reader3 & $\begin{array}{l}0.75 \\
(0.60- \\
0.86)\end{array}$ & $\begin{array}{l}0.87 \\
(0.74- \\
0.95)\end{array}$ & $\begin{array}{l}0.80 \\
(0.71- \\
0.88)\end{array}$ & $\begin{array}{l}0.81 \\
(0.73- \\
0.89)\end{array}$ & 0.167 \\
\hline
\end{tabular}




\begin{tabular}{|c|c|c|c|c|c|c|}
\hline Image set & Interpreter & Sensitivity & Specificity & Accuracy & AUC & $\begin{array}{l}P \text { value } \\
\text { for AUC } \\
\text { (vs. } \\
\text { CNN) }\end{array}$ \\
\hline \multirow[t]{4}{*}{ Axial CE-T1WI } & CNN & $\begin{array}{l}0.84 \\
(0.71- \\
0.93)\end{array}$ & $\begin{array}{l}0.89 \\
(0.76- \\
0.96)\end{array}$ & $\begin{array}{l}0.87 \\
(0.78- \\
0.93)\end{array}$ & $\begin{array}{l}0.93 \\
(0.87- \\
0.98)\end{array}$ & - \\
\hline & Reader1 & $\begin{array}{l}0.75 \\
(0.60- \\
0.86)\end{array}$ & $\begin{array}{l}0.94 \\
(0.82- \\
0.99)\end{array}$ & $\begin{array}{l}0.84 \\
(0.75- \\
0.90)\end{array}$ & $\begin{array}{l}0.84 \\
(0.77- \\
0.91)\end{array}$ & $0.006^{*}$ \\
\hline & Reader2 & $\begin{array}{l}0.77 \\
(0.63- \\
0.87)\end{array}$ & $\begin{array}{l}0.91 \\
(0.79- \\
0.98)\end{array}$ & $\begin{array}{l}0.84 \\
(0.75- \\
0.90)\end{array}$ & $\begin{array}{l}0.84 \\
(0.77- \\
0.91)\end{array}$ & $0.002^{*}$ \\
\hline & Reader3 & $\begin{array}{l}0.77 \\
(0.63- \\
0.87)\end{array}$ & $\begin{array}{l}0.91 \\
(0.79- \\
0.98)\end{array}$ & $\begin{array}{l}0.84 \\
(0.75- \\
0.90)\end{array}$ & $\begin{array}{l}0.84 \\
(0.77- \\
0.91)\end{array}$ & $0.014^{\star}$ \\
\hline \multirow[t]{4}{*}{ Sagittal CE-T1WI } & CNN & $\begin{array}{l}0.90 \\
(0.83- \\
0.95)\end{array}$ & $\begin{array}{l}0.83 \\
(0.74- \\
0.88)\end{array}$ & $\begin{array}{l}0.87 \\
(0.79- \\
0.92)\end{array}$ & $\begin{array}{l}0.90 \\
(0.84- \\
0.97)\end{array}$ & - \\
\hline & Reader1 & $\begin{array}{l}0.78 \\
(0.65- \\
0.89)\end{array}$ & $\begin{array}{l}0.94 \\
(0.82- \\
0.99)\end{array}$ & $\begin{array}{l}0.86 \\
(0.77- \\
0.92)\end{array}$ & $\begin{array}{l}0.86 \\
(0.79- \\
0.93)\end{array}$ & 0.336 \\
\hline & Reader2 & $\begin{array}{l}0.73 \\
(0.58- \\
0.84)\end{array}$ & $\begin{array}{l}0.96 \\
(0.85- \\
1.00)\end{array}$ & $\begin{array}{l}0.84 \\
(0.75- \\
0.90)\end{array}$ & $\begin{array}{l}0.84 \\
(0.77- \\
0.91)\end{array}$ & 0.173 \\
\hline & Reader3 & $\begin{array}{l}0.84 \\
(0.71- \\
0.93)\end{array}$ & $\begin{array}{l}0.87 \\
(0.74- \\
0.95)\end{array}$ & $\begin{array}{l}0.86 \\
(0.77- \\
0.92)\end{array}$ & $\begin{array}{l}0.86 \\
(0.79- \\
0.93)\end{array}$ & 0.341 \\
\hline \multirow[t]{4}{*}{$\begin{array}{l}\text { Combined axial T2WI + } \\
\text { ADC map }\end{array}$} & CNN & $\begin{array}{l}0.82 \\
(0.69- \\
0.92)\end{array}$ & $\begin{array}{l}0.87 \\
(0.74- \\
0.95)\end{array}$ & $\begin{array}{l}0.85 \\
(0.76- \\
0.91)\end{array}$ & $\begin{array}{l}0.93 \\
(0.88- \\
0.98)\end{array}$ & - \\
\hline & Reader1 & $\begin{array}{l}0.73 \\
(0.58- \\
0.84)\end{array}$ & $\begin{array}{l}0.96 \\
(0.85- \\
1.00)\end{array}$ & $\begin{array}{l}0.84 \\
(0.75- \\
0.90)\end{array}$ & $\begin{array}{l}0.58 \\
(0.48- \\
0.68)\end{array}$ & $<0.001^{\star}$ \\
\hline & Reader2 & $\begin{array}{l}0.84 \\
(0.71- \\
0.93)\end{array}$ & $\begin{array}{l}0.98 \\
(0.89- \\
1.00)\end{array}$ & $\begin{array}{l}0.91 \\
(0.83- \\
0.96)\end{array}$ & $\begin{array}{l}0.91 \\
(0.86- \\
0.97)\end{array}$ & 0.598 \\
\hline & Reader3 & $\begin{array}{l}0.88 \\
(0.76- \\
0.96)\end{array}$ & $\begin{array}{l}0.87 \\
(0.74- \\
0.95)\end{array}$ & $\begin{array}{l}0.88 \\
(0.79- \\
0.93)\end{array}$ & $\begin{array}{l}0.88 \\
(0.81- \\
0.94)\end{array}$ & 0.196 \\
\hline
\end{tabular}

Diagnostic performance of the CNNs and radiologists in the test using single and combined image sets. 


\begin{tabular}{|c|c|c|c|c|c|c|}
\hline Image set & Interpreter & Sensitivity & Specificity & Accuracy & AUC & $\begin{array}{l}\text { Pvalue } \\
\text { for AUC } \\
\text { (vs. } \\
\text { CNN) }\end{array}$ \\
\hline \multirow[t]{4}{*}{$\begin{array}{l}\text { Combined axial T2WI + } \\
\text { CE-T1WI }\end{array}$} & CNN & $\begin{array}{l}0.84 \\
(0.71- \\
0.93)\end{array}$ & $\begin{array}{l}0.91 \\
(0.79- \\
0.98)\end{array}$ & $\begin{array}{l}0.88 \\
(0.79- \\
0.93)\end{array}$ & $\begin{array}{l}0.89 \\
(0.83- \\
0.96)\end{array}$ & - \\
\hline & Reader1 & $\begin{array}{l}0.80 \\
(0.67- \\
0.90)\end{array}$ & $\begin{array}{l}0.98 \\
(0.89- \\
1.00)\end{array}$ & $\begin{array}{l}0.89 \\
(0.81- \\
0.94)\end{array}$ & $\begin{array}{l}0.89 \\
(0.83- \\
0.95)\end{array}$ & 0.943 \\
\hline & Reader2 & $\begin{array}{l}0.80 \\
(0.67- \\
0.90)\end{array}$ & $\begin{array}{l}0.96 \\
(0.85- \\
1.00)\end{array}$ & $\begin{array}{l}0.88 \\
(0.79- \\
0.93)\end{array}$ & $\begin{array}{l}0.88 \\
(0.82- \\
0.94)\end{array}$ & 0.720 \\
\hline & Reader3 & $\begin{array}{l}0.92 \\
(0.81- \\
0.98)\end{array}$ & $\begin{array}{l}0.85 \\
(0.71- \\
0.94)\end{array}$ & $\begin{array}{l}0.89 \\
(0.81- \\
0.94)\end{array}$ & $\begin{array}{l}0.89 \\
(0.82- \\
0.95)\end{array}$ & 0.839 \\
\hline \multirow[t]{4}{*}{$\begin{array}{l}\text { Combined sagittal } \\
\text { T2WI + CE-T1WI }\end{array}$} & CNN & $\begin{array}{l}0.94 \\
(0.84- \\
0.99)\end{array}$ & $\begin{array}{l}0.74 \\
(0.59- \\
0.86)\end{array}$ & $\begin{array}{l}0.85 \\
(0.76- \\
0.91)\end{array}$ & $\begin{array}{l}0.89 \\
(0.82- \\
0.95)\end{array}$ & - \\
\hline & Reader1 & $\begin{array}{l}0.80 \\
(0.67- \\
0.90)\end{array}$ & $\begin{array}{l}0.98 \\
(0.89- \\
1.00)\end{array}$ & $\begin{array}{l}0.89 \\
(0.81- \\
0.94)\end{array}$ & $\begin{array}{l}0.89 \\
(0.83- \\
0.95)\end{array}$ & 0.890 \\
\hline & Reader2 & $\begin{array}{l}0.69 \\
(0.54- \\
0.81)\end{array}$ & $\begin{array}{l}1.00 \\
(0.89- \\
1.00)\end{array}$ & $\begin{array}{l}0.84 \\
(0.75- \\
0.90)\end{array}$ & $\begin{array}{l}0.84 \\
(0.78- \\
0.91)\end{array}$ & 0.375 \\
\hline & Reader3 & $\begin{array}{l}0.86 \\
(0.74- \\
0.94)\end{array}$ & $\begin{array}{l}0.87 \\
(0.74- \\
0.95)\end{array}$ & $\begin{array}{l}0.87 \\
(0.78- \\
0.93)\end{array}$ & $\begin{array}{l}0.87 \\
(0.80- \\
0.94)\end{array}$ & 0.667 \\
\hline \multirow{4}{*}{$\begin{array}{l}\text { Combined axial } \\
\text { T2WI + ADC map + CE- } \\
\text { T1WI }\end{array}$} & CNN & $\begin{array}{l}0.80 \\
(0.67- \\
0.90)\end{array}$ & $\begin{array}{l}0.80 \\
(0.66- \\
0.91)\end{array}$ & $\begin{array}{l}0.80 \\
(0.71- \\
0.88)\end{array}$ & $\begin{array}{l}0.87 \\
(0.80- \\
0.94)\end{array}$ & - \\
\hline & Reader1 & $\begin{array}{l}0.71 \\
(0.56- \\
0.83)\end{array}$ & $\begin{array}{l}1.00 \\
(0.89- \\
1.00)\end{array}$ & $\begin{array}{l}0.85 \\
(0.76- \\
0.91)\end{array}$ & $\begin{array}{l}0.85 \\
(0.79- \\
0.92)\end{array}$ & 0.675 \\
\hline & Reader2 & $\begin{array}{l}0.67 \\
(0.52- \\
0.79)\end{array}$ & $\begin{array}{l}1.00 \\
(0.89- \\
1.00)\end{array}$ & $\begin{array}{l}0.83 \\
(0.73- \\
0.89)\end{array}$ & $\begin{array}{l}0.83 \\
(0.77- \\
0.90)\end{array}$ & 0.406 \\
\hline & Reader3 & $\begin{array}{l}0.78 \\
(0.65- \\
0.89)\end{array}$ & $\begin{array}{l}0.94 \\
(0.82- \\
0.99)\end{array}$ & $\begin{array}{l}0.86 \\
(0.77- \\
0.92)\end{array}$ & $\begin{array}{l}0.86 \\
(0.79- \\
0.93)\end{array}$ & 0.813 \\
\hline
\end{tabular}


AUC, area under the receiver operating characteristic curve; Data in parentheses are $95 \%$ confidence interval. ${ }^{\star} P<0.05$.

Figure 5 Three cases of false negatives observed in the single image set of axial ADC: (a) A 55-year-old women with grade 1 endometrioid carcinoma, in which the CNN was able to diagnose the cancer, but the readers 1,2 , and 3 were not (the CNN confidence; cancer $=99.9 \%$ ). The image shows a tiny tumor filling the uterine cavity (arrow); (b) A 34-year-old women with grade 1 endometrioid carcinoma, in which all the three readers could diagnose cancer, but the CNN could not (the CNN confidence; cancer $=18.8 \%$ ). The image shows a massive tumor protruding into the myometrium of the posterior wall of the uterus (arrow); (c) A 31-year-old women with grade 2 endometrioid carcinoma, in which neither the CNN nor the three readers could diagnose the presence of cancer (the $\mathrm{CNN}$ confidence; cancer $=22.5 \%$ ). The image shows the tumor filling the uterine cavity (arrow). A slight decrease in ADC map might have made the diagnosis of tumor difficult with a single image, without considering the other images for radiologists.

\subsection{Experiment 2}

The results of Experiment 2 are presented in Table 5 and Figure 7. Table 5 shows the diagnostic performance of the CNNs in the testing using single image sets and the addition of various types of image sets of different sequences and/or cross-sections to the training data. In this study, the AUC showed an increase when any types of image sets added for training in sagittal T2WI and sagittal CE$\mathrm{T} 1 \mathrm{WI}$, and all T2WI and all image sets were used for training in axial T2WI, although the difference was not significant. Conversely, for axial ADC map and axial CE-T1WI, the addition of any image set for training did not improve the AUC. 
Table 5

Experiment 2-Diagnostic performance of the CNNs

\begin{tabular}{|c|c|c|c|c|c|c|}
\hline $\begin{array}{l}\text { Test image } \\
\text { set }\end{array}$ & $\begin{array}{l}\text { Training } \\
\text { image set }\end{array}$ & Sensitivity & Specificity & Accuracy & AUC & $\begin{array}{l}P \text {-value for } \\
\text { AUC }^{+}\end{array}$ \\
\hline \multirow[t]{3}{*}{$\begin{array}{l}\text { Axial ADC } \\
\text { map }\end{array}$} & $\begin{array}{l}\text { Axial ADC } \\
\text { map }\end{array}$ & $\begin{array}{l}0.94(0.87- \\
0.98)\end{array}$ & $\begin{array}{l}0.87(0.79- \\
0.91)\end{array}$ & $\begin{array}{l}0.91(0.83- \\
0.95)\end{array}$ & $\begin{array}{l}0.95(0.91- \\
1.00)\end{array}$ & - \\
\hline & All axial & $\begin{array}{l}0.84(0.76- \\
0.90)\end{array}$ & $\begin{array}{l}0.87(0.78- \\
0.93)\end{array}$ & $\begin{array}{l}0.86(0.77- \\
0.91)\end{array}$ & $\begin{array}{l}0.93(0.87- \\
0.98)\end{array}$ & 0.345 \\
\hline & All & $\begin{array}{l}0.90(0.82- \\
0.95)\end{array}$ & $\begin{array}{l}0.80(0.72- \\
0.86)\end{array}$ & $\begin{array}{l}0.86(0.77- \\
0.91)\end{array}$ & $\begin{array}{l}0.89(0.81- \\
0.96)\end{array}$ & 0.069 \\
\hline \multirow[t]{4}{*}{ Axial T2WI } & Axial T2WI & $\begin{array}{l}0.90(0.83- \\
0.95)\end{array}$ & $\begin{array}{l}0.83(0.74- \\
0.88)\end{array}$ & $\begin{array}{l}0.87(0.79- \\
0.92)\end{array}$ & $\begin{array}{l}0.90(0.84- \\
0.96)\end{array}$ & - \\
\hline & All T2WI & $\begin{array}{l}0.92(0.85- \\
0.96)\end{array}$ & $\begin{array}{l}0.89(0.81- \\
0.94)\end{array}$ & $\begin{array}{l}0.91(0.83- \\
0.95)\end{array}$ & $\begin{array}{l}0.94 \rrbracket(0.88- \\
0.99)\end{array}$ & 0.218 \\
\hline & All axial & $\begin{array}{l}0.86(0.79- \\
0.91)\end{array}$ & $\begin{array}{l}0.87(0.78- \\
0.93)\end{array}$ & $\begin{array}{l}0.87(0.78- \\
0.92)\end{array}$ & $\begin{array}{l}0.90(0.84- \\
0.97)\end{array}$ & 0.934 \\
\hline & All & $\begin{array}{l}0.90(0.83- \\
0.95)\end{array}$ & $\begin{array}{l}0.85(0.76- \\
0.90)\end{array}$ & $\begin{array}{l}0.88(0.80- \\
0.93)\end{array}$ & $\begin{array}{l}0.91 \rrbracket(0.85- \\
0.98)\end{array}$ & 0.627 \\
\hline \multirow[t]{4}{*}{$\begin{array}{l}\text { Sagittal } \\
\text { T2WI }\end{array}$} & $\begin{array}{l}\text { Sagittal } \\
\text { T2WI }\end{array}$ & $\begin{array}{l}0.90(0.82- \\
0.95)\end{array}$ & $\begin{array}{l}0.80(0.72- \\
0.86)\end{array}$ & $\begin{array}{l}0.86(0.77- \\
0.91)\end{array}$ & $\begin{array}{l}0.88(0.81- \\
0.95)\end{array}$ & - \\
\hline & All T2WI & $\begin{array}{l}0.94(0.87- \\
0.98)\end{array}$ & $\begin{array}{l}0.80(0.72- \\
0.85)\end{array}$ & $\begin{array}{l}0.88(0.80- \\
0.92)\end{array}$ & $\begin{array}{l}0.92 \rrbracket(0.86- \\
0.98)\end{array}$ & 0.188 \\
\hline & All sagittal & $\begin{array}{l}0.90(0.83- \\
0.95)\end{array}$ & $\begin{array}{l}0.83(0.74- \\
0.88)\end{array}$ & $\begin{array}{l}0.87(0.79- \\
0.92)\end{array}$ & $\begin{array}{l}0.91 \rrbracket(0.84- \\
0.97)\end{array}$ & 0.507 \\
\hline & All & $\begin{array}{l}0.86(0.79- \\
0.91)\end{array}$ & $\begin{array}{l}0.87(0.78- \\
0.93)\end{array}$ & $\begin{array}{l}0.87(0.78- \\
0.92)\end{array}$ & $\begin{array}{l}0.92 \rrbracket(0.85- \\
0.98)\end{array}$ & 0.424 \\
\hline \multirow[t]{4}{*}{$\begin{array}{l}\text { Axial CE- } \\
\text { T1WI }\end{array}$} & $\begin{array}{l}\text { Axial CE- } \\
\text { T1WI }\end{array}$ & $\begin{array}{l}0.84(0.71- \\
0.93)\end{array}$ & $\begin{array}{l}0.89(0.76- \\
0.96)\end{array}$ & $\begin{array}{l}0.87(0.78- \\
0.93)\end{array}$ & $\begin{array}{l}0.93(0.87- \\
0.98)\end{array}$ & - \\
\hline & All CE-T1WI & $\begin{array}{l}0.84(0.77- \\
0.89)\end{array}$ & $\begin{array}{l}0.91(0.83- \\
0.96)\end{array}$ & $\begin{array}{l}0.88(0.80- \\
0.92)\end{array}$ & $\begin{array}{l}0.93(0.89- \\
0.98)\end{array}$ & 0.716 \\
\hline & All axial & $\begin{array}{l}0.92(0.85- \\
0.97)\end{array}$ & $\begin{array}{l}0.78(0.70- \\
0.83)\end{array}$ & $\begin{array}{l}0.86(0.78- \\
0.90)\end{array}$ & $\begin{array}{l}0.88(0.80- \\
0.95)\end{array}$ & 0.086 \\
\hline & All & $\begin{array}{l}0.86(0.78- \\
0.92)\end{array}$ & $\begin{array}{l}0.84(0.76- \\
0.91)\end{array}$ & $\begin{array}{l}0.86(0.77- \\
0.91)\end{array}$ & $\begin{array}{l}0.91(0.85- \\
0.97)\end{array}$ & 0.589 \\
\hline
\end{tabular}

Diagnostic performance of the CNNs in the testing using single image sets with the addition of other image sets for training.

${ }^{\dagger}$ vs. the CNN trained with single image set 


\begin{tabular}{|c|c|c|c|c|c|c|}
\hline $\begin{array}{l}\text { Test image } \\
\text { set }\end{array}$ & $\begin{array}{l}\text { Training } \\
\text { image set }\end{array}$ & Sensitivity & Specificity & Accuracy & AUC & $\begin{array}{l}\text { P-value for } \\
\text { AUC }^{+}\end{array}$ \\
\hline \multirow[t]{4}{*}{$\begin{array}{l}\text { Sagittal CE- } \\
\text { T1WI }\end{array}$} & $\begin{array}{l}\text { Sagittal CE- } \\
\text { T1WI }\end{array}$ & $\begin{array}{l}0.90(0.83- \\
0.95)\end{array}$ & $\begin{array}{l}0.83(0.74- \\
0.88)\end{array}$ & $\begin{array}{l}0.87(0.79- \\
0.92)\end{array}$ & $\begin{array}{l}0.90(0.84- \\
0.97)\end{array}$ & - \\
\hline & All CE-T1WI & $\begin{array}{l}0.86(0.79- \\
0.91)\end{array}$ & $\begin{array}{l}0.87(0.78- \\
0.93)\end{array}$ & $\begin{array}{l}0.87(0.78- \\
0.92)\end{array}$ & 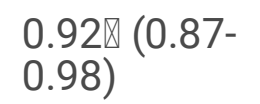 & 0.524 \\
\hline & All sagittal & $\begin{array}{l}0.90(0.83- \\
0.95)\end{array}$ & $\begin{array}{l}0.85(0.76- \\
0.90)\end{array}$ & $\begin{array}{l}0.88(0.80- \\
0.93)\end{array}$ & $\begin{array}{l}0.91 \otimes(0.85- \\
0.98)\end{array}$ & 0.696 \\
\hline & All & $\begin{array}{l}0.98(0.92- \\
1.00)\end{array}$ & $\begin{array}{l}0.83(0.76- \\
0.84)\end{array}$ & $\begin{array}{l}0.91(0.84- \\
0.92)\end{array}$ & $\begin{array}{l}0.95 \bigotimes(0.89- \\
1.00)\end{array}$ & 0.156 \\
\hline \multicolumn{7}{|c|}{$\begin{array}{l}\text { Diagnostic performance of the CNNs in the testing using single image sets with the addition of other } \\
\text { image sets for training. }\end{array}$} \\
\hline
\end{tabular}

\section{Discussion}

The CNNs displayed better diagnostic performance in interpreting all five single image sets and significantly better results with single axial ADC map and axial CE-T1WI, compared to the radiologists. Although there were no significant differences, the diagnostic performance was improved by adding other types of image sets to the training data, except for axial ADC map and axial CE-T1WI. The improvement in the interpretation of the combined image sets was not equivalent to that of the radiologists.

Several CNNs using MRI have been constructed for the diagnosis of uterine tumors to date $(19,20)$. Urushibara et al. recently developed a CNN that can differentiate between cervical cancer and noncancerous lesions on T2WI (21). Chen et al. and Dong et al. evaluated the myometrial infiltration of endometrial cancer using CNN and T2WI (22), and T2WI + CE-T1WI (23). As far as we know, this is the first study to diagnose the presence of endometrial cancer and to assess the effects of adding other types of images to the training data and the conditions suitable for the application of deep learning in tumor classification. It is also noteworthy that the entire pelvic images were used, not just the cropped images of the uterus.

CE-T1WI and DWI are important sequences that allow the functional evaluation of endometrial cancer, and are clinically used as an adjunct to T2WI. The degree of tumor enhancement depends on the tumor vascularity; most endometrial cancers are hypovascular, while quite a few are isovascular or hypervascular, compared to the myometrium (24). ADC values are inversely correlated to the tumor cellularity (25), and ADC values of endometrial cancer are significantly lower, compared to endometrial polyps and normal endometrium $(26,27)$. Hence, referencing CE-T1WI and ADC map with T2WI improves the diagnosis of cancer. The present study observed that the CNNs displayed the best performance with single axial ADC map in Experiment 1, which is consistent with a previous study regarding the diagnosis 
of prostate cancer. The perception of anatomical structures using ADC map alone is challenging for the radiologists. In contrast, $A D C$ maps are considered to be suitable for cancer detection using $C N N$, and showing high diagnostic performance on $A D C$ map with low spatial resolution alone may be one of the CNN's strengths. Contrary to the current results, Aldoj et al. reported that the best diagnostic performance of the CNN was attained by combining ADC map + DWI + perfusion + T2WI (28). This research differs from the present study in that a large number of (approximately 120,000) images were used for training. As the number of images to be combined increases, the variation in information also increases. Consequently, increasing the number of images used for training may be warranted.

Adding other types of image sets to the training data improved the diagnostic performance, except for the axial ADC map and axial CE-T1WI in Experiment 2. This result is similar to the recent report by Lee et al. that training with all available MRI sequences of the same cross-section improves the diagnostic performance of CNNs in distinguishing between pseudo and true tumor progression (29). The present study observed that the addition of other cross-sections of the same sequence was especially beneficial. The amount of training data for the sagittal sections was smaller, compared to the axial sections. Hence, the impact of the improvement may be greater. It is presumed that similar signal information is included in the same sequence even in different cross-sections, and similar morphological information is included in the same cross-section, even in different sequences. The potential for improved diagnostic performance by adding different sequences and cross-sections is an important result concerning the deep learning studies of tumor diagnosis, which involve difficulties in obtaining a large number of images. In order to establish the optimum image conditions in deep learning using MR images with various sequences and cross sections, it is necessary to further verify using various combinations of various images in various regions.

The current study has several limitations. First, only one selected image was evaluated, which differs from the clinical practice of diagnosis using a series of images. It also differs from a clinical setting in that the JPEG images, which contain less information than DICOM images, were used. Second, the noncancer group included lesions that were not pathologically confirmed. However, we considered it important to distinguish cancer from benign lesions that do not warrant treatment. Third, it is controversial whether atypical endometrial hyperplasia should be classified as benign because it is not cancerous or malignant because it is a precursor lesion. However, it would be unreasonable to exclude only atypical endometrial hyperplasia from this study. Therefore, in this study, we classified atypical endometrial hyperplasia as benign because the purpose was to detect endometrial cancer. Fourth, we have not examined dynamic studies to avoid study complexity. Although dynamic study is useful to determine the degree of myometrial invasion, contrast between the tumor and the myometrium is greatest during the equilibrium phase (3). This study targeted the presence of cancer, so only images of the equilibrium phase were used as contrast images. The following can be considered future improvements: the superiority of combined images may be demonstrated using more training data. The performance can be improved using three-dimensional images instead of two-dimensional images, as reported by Mehrtash et al., who used three-dimensional prostate images for convolutional neural networks (30). Evaluation with DICOM data and learning with clinical data such as tumor markers can also improve 
diagnostic performance. Further versatility can be achieved using the images obtained with other MRI equipment.

\section{Conclusions}

In conclusion, deep learning demonstrated high diagnostic performance in diagnosing the presence of endometrial cancer on MRI. In particular, a deep learning model using convolutional neural networks showed significantly better results with single axial apparent diffusion coefficient of water maps and axial contrast-enhanced T1-weighted images, compared to expert radiologists. Moreover, although there were no significant differences, the addition of other types of images to the training data improved the diagnostic performance for some of the single image sets.

\section{Abbreviations}

CNNs: Deep learning models using convolutional neural networks, T2WI, T2-weighted image, ADC, apparent diffusion coefficient of water, CE-T1WI, contrast-enhanced fat-saturated T1-weighted image, DWI, Diffusion weighted image, DICOM, Digital imaging and communications in medicine, JPEG, Joint photographic experts group, ROC, Receiver operating characteristic, $\mathrm{Cl}$, Confidence interval, AUC, Area under the receiver operating characteristic curve

\section{Declarations}

\section{Ethics approval and consent to participate}

The study was conducted according to the guidelines of the Declaration of Helsinki, and approved by the Ethics Committee of the University of Tsukuba Hospital (approval number: R02-054, 9 June 2020). And the need to obtain informed consent was waived by the Ethics Committee of the University of Tsukuba Hospital because of de-identification data involving no potential risk to patients.

\section{Consent for publication}

Not applicable.

\section{Availability of Data and Material (ADM)}

The datasets generated and analyzed during the current study are not publicly available due to ethical considerations but are available from the corresponding author on reasonable request.

\section{Competing interests}

The authors declare no competing interests.

\section{Funding}


This research received no external funding.

\section{Authors' contributions}

Conceptualization, A.U. and T.S., methodology, A.U., T.S. and K.M., software, A.U. and T.S., validation, T.S., K.I. and T.S., formal analysis, A.U. and T.S., investigation, A.U., T.S., K.M., T.I. and T.M., resources, T.S., data curation, A.U. and T.S., writing-original draft preparation, A.U., writing-review and editing, T.S., K.M., T.I., K.I., T.M., T.S. and T.N., supervision, T.N., project administration, T.N. All authors have read and agreed to the published version of the manuscript.

\section{Acknowledgment}

Not applicable.

\section{References}

1. Sung H, Ferlay J, Siegel RL, Laversanne M, Soerjomataram I, Jemal A, et al. Global Cancer Statistics 2020: GLOBOCAN Estimates of Incidence and Mortality Worldwide for 36 Cancers in 185 Countries. CA Cancer J Clin. 2021,71(3):209-49.

2. Constantine GD, Kessler G, Graham S, Goldstein SR. Increased Incidence of Endometrial Cancer Following the Women's Health Initiative: An Assessment of Risk Factors. J Womens Health (Larchmt). 2019,28(2):237-43.

3. Sala E, Wakely S, Senior E, Lomas D. MRI of malignant neoplasms of the uterine corpus and cervix. AJR Am J Roentgenol. 2007,188(6):1577-87.

4. Beddy P, Moyle P, Kataoka M, Yamamoto AK, Joubert I, Lomas D, et al. Evaluation of depth of myometrial invasion and overall staging in endometrial cancer: comparison of diffusion-weighted and dynamic contrast-enhanced MR imaging. Radiology. 2012,262(2):530-7.

5. Nougaret S, Horta M, Sala E, Lakhman Y, Thomassin-Naggara I, Kido A, et al. Endometrial Cancer MRI staging: Updated Guidelines of the European Society of Urogenital Radiology. Eur Radiol. 2019,29(2):792-805.

6. Lundervold AS, Lundervold A. An overview of deep learning in medical imaging focusing on MRI. Z Med Phys. 2019,29(2):102-27.

7. Fujioka T, Mori M, Kubota K, Oyama J, Yamaga E, Yashima Y, et al. The Utility of Deep Learning in Breast Ultrasonic Imaging: A Review. Diagnostics (Basel). 2020,10(12).

8. Kurata Y, Nishio M, Kido A, Fujimoto K, Yakami M, Isoda H, et al. Automatic segmentation of the uterus on MRI using a convolutional neural network. Comput Biol Med. 2019,114:103438.

9. Soffer S, Ben-Cohen A, Shimon O, Amitai MM, Greenspan H, Klang E. Convolutional Neural Networks for Radiologic Images: A Radiologist's Guide. Radiology. 2019,290(3):590-606.

10. Hodneland E, Dybvik JA, Wagner-Larsen KS, Solteszova V, Munthe-Kaas AZ, Fasmer KE, et al. Automated segmentation of endometrial cancer on MR images using deep learning. Sci Rep. 
2021,11(1):179.

11. Adachi M, Fujioka T, Mori M, Kubota K, Kikuchi Y, Xiaotong W, et al. Detection and Diagnosis of Breast Cancer Using Artificial Intelligence Based assessment of Maximum Intensity Projection Dynamic Contrast-Enhanced Magnetic Resonance Images. Diagnostics (Basel). 2020,10(5).

12. Gauriau R, Bizzo BC, Kitamura FC, Landi Junior O, Ferraciolli SF, Macruz FBC, et al. A Deep Learningbased Model for Detecting Abnormalities on Brain MR Images for Triaging: Preliminary Results from a Multisite Experience. Radiol Artif Intell. 2021,3(4):e200184.

13. Fujioka T, Katsuta L, Kubota K, Mori M, Kikuchi Y, Kato A, et al. Classification of breast masses on ultrasound shear wave elastography using convolutional neural networks. Ultrason Imaging. 2020:161734620932609.

14. Schelb P, Kohl S, Radtke JP, Wiesenfarth $M$, Kickingereder P, Bickelhaupt $S$, et al. Classification of Cancer at Prostate MRI: Deep Learning versus Clinical PI-RADS Assessment. Radiology. 2019,293(3):607-17.

15. The ImageMagick Development Team. ImageMagick. https://imagemagickorg. 2021.

16. Chollet. F. Xception: Deep learning with depthwise separa-ble convolutions. 2017 IEEE Conference on Computer Vision and Pattern Recognition (CVPR). 2017:1800-7.

17. Russakovsky O, Deng J, Su H, Krause J, Satheesh S, Ma S, et al. ImageNet Large Scale Visual Recognition Challenge. International Journal of Computer Vision. 2015,115(3):211-52.

18. Linden A. Measuring diagnostic and predictive accuracy in disease management: an introduction to receiver operating characteristic (ROC) analysis. J Eval Clin Pract. 2006,12(2):132-9.

19. Zhou J, Zeng ZY, Li L. Progress of Artificial Intelligence in Gynecological Malignant Tumors. Cancer Manag Res. 2020,12:12823-40.

20. Wu Q, Wang S, Zhang S, Wang M, Ding Y, Fang J, et al. Development of a Deep Learning Model to Identify Lymph Node Metastasis on Magnetic Resonance Imaging in Patients With Cervical Cancer. JAMA Netw Open. 2020,3(7):e2011625.

21. Urushibara A, Saida T, Mori K, Ishiguro T, Sakai M, Masuoka S, et al. Diagnosing uterine cervical cancer on a single T2-weighted image: Comparison between deep learning versus radiologists. Eur $\mathrm{J}$ Radiol. 2020,135:109471.

22. Chen $X$, Wang $Y$, Shen $M$, Yang $B$, Zhou Q, Yi Y, et al. Deep learning for the determination of myometrial invasion depth and automatic lesion identification in endometrial cancer MR imaging: a preliminary study in a single institution. Eur Radiol. 2020,30(9):4985-94.

23. Dong HC, Dong HK, Yu MH, Lin YH, Chang CC. Using Deep Learning with Convolutional Neural Network Approach to Identify the Invasion Depth of Endometrial Cancer in Myometrium Using MR Images: A Pilot Study. Int J Environ Res Public Health. 2020,17(16).

24. Whittaker CS, Coady A, Culver L, Rustin G, Padwick M, Padhani AR. Diffusion-weighted MR imaging of female pelvic tumors: a pictorial review. Radiographics. 2009,29(3):759-74, discussion 74-8.

25. Funt SA, Hricak H. Ovarian malignancies. Top Magn Reson Imaging. 2003,14(4):329-37. 
26. Fujii S, Matsusue E, Kigawa J, Sato S, Kanasaki Y, Nakanishi J, et al. Diagnostic accuracy of the apparent diffusion coefficient in differentiating benign from malignant uterine endometrial cavity lesions: initial results. Eur Radiol. 2008,18(2):384-9.

27. Tamai K, Koyama T, Saga T, Umeoka S, Mikami Y, Fujii S, et al. Diffusion-weighted MR imaging of uterine endometrial cancer. J Magn Reson Imaging. 2007,26(3):682-7.

28. Aldoj N, Lukas S, Dewey M, Penzkofer T. Semi-automatic classification of prostate cancer on multiparametric MR imaging using a multi-channel 3D convolutional neural network. Eur Radiol. 2020,30(2):1243-53.

29. Lee J, Wang N, Turk S, Mohammed S, Lobo R, Kim J, et al. Discriminating pseudoprogression and true progression in diffuse infiltrating glioma using multi-parametric MRI data through deep learning. Sci Rep. 2020,10(1):20331.

30. Mehrtash A, Sedghi A, Ghafoorian M, Taghipour M, Tempany CM, Wells WM, 3rd, et al. Classification of Clinical Significance of MRI Prostate Findings Using 3D Convolutional Neural Networks. Proc SPIE Int Soc Opt Eng. 2017,10134.

\section{Figures}

2421 patients underwent pelvic MRI at our hospital during the time period from January 2015 to May 2020

\begin{tabular}{|c|c|}
\hline $\begin{array}{c}602 \text { patients under the age of } 20 \text { years } \\
\text { other than endometrial cancer }\end{array}$ \\
sequences evaluated in the current study
\end{tabular}

\section{Figure 1}

Flowchart of the patient selection process 
a Schematic diagrams of Experiment 1

b Schematic diagrams of Experiment 2

\section{Figure 3}

Experiment 1-The ROC curves for the CNNs

The ROC curves for the CNNs pertaining to the testing of single and combined image sets with the AUC plots for the radiologists.

\section{Figure 4}

Accuracy and loss of the training data of single axial ADC map

Accuracy and loss of the training data of single axial ADC map with the training/validation split ratio 9:1 and epoch 100 in Experiment 1.

Acc., accuracy.
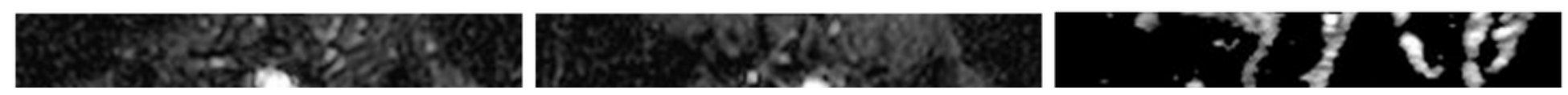

\section{Figure 5}

Three cases of false negatives observed in the single image set of axial ADC: (a) A 55-year-old women with grade 1 endometrioid carcinoma, in which the CNN was able to diagnose the cancer, but the readers 
1,2 , and 3 were not (the CNN confidence, cancer $=99.9 \%$ ). The image shows a tiny tumor filling the uterine cavity (arrow), (b) A 34-year-old women with grade 1 endometrioid carcinoma, in which all the three readers could diagnose cancer, but the $\mathrm{CNN}$ could not (the $\mathrm{CNN}$ confidence, cancer $=18.8 \%$ ). The image shows a massive tumor protruding into the myometrium of the posterior wall of the uterus (arrow), (c) A 31-year-old women with grade 2 endometrioid carcinoma, in which neither the CNN nor the three readers could diagnose the presence of cancer (the $C N N$ confidence, cancer $=22.5 \%$ ). The image shows the tumor filling the uterine cavity (arrow). A slight decrease in ADC map might have made the diagnosis of tumor difficult with a single image, without considering the other images for radiologists.

\section{Figure 6}

Three cases of false negatives observed in the combined image set of axial T2WI+ADC+CE-T1WI: (a) A 56-year-old women with grade 1 endometrioid carcinoma, in which the CNN was able to detect the cancer, but the three readers were not (the CNN confidence, cancer=100\%), (b) A 30-year-old women with grade 1 endometrioid carcinoma, in which the three readers could diagnose the presence of cancer, but the CNN could not (the CNN confidence, cancer $=0.5 \%$ ). The image shows a tumor displaying the typical appearance of endometrial cancer and filling the right side of the uterine cavity (arrow), (c) A 45-year-old women with grade 1 endometrioid carcinoma, in which neither the CNN nor the three readers could diagnose the presence of cancer (the $C N N$ confidence, cancer $=0.5 \%$ ). The image shows a massive tumor filling the uterine cavity (arrow) and a hemorrhage at the center of the lesion. Non-uniform signal intensities of the tumor mass may have made the diagnosis difficult for radiologists.

\section{Figure 7}

Experiment 2 - The ROC curves for the CNNs

The ROC curves for the CNNs pertaining to testing the single image sets with various types of image sets for training. 